\title{
Ureterdynamic Analysis of Multiple Peristaltic Waves on Variable Diameter Ureter
}

\author{
Laxmikant G Keni, ${ }^{1}$ Mattias Jan Hayoz, ${ }^{2}$ Satish Shenoy B, ${ }^{1}$ Padmaraj Hegde, ${ }^{3}$ Prakashini K, ${ }^{4}$ Masaaki Tamagawa, ${ }^{5}$ Shah
} Mohammad Abdul Khader ${ }^{6}$ and Mohammad Zuber ${ }^{1 *}$

\begin{abstract}
In ureter physiology, the peristaltic mechanism is involved in urine transport from the kidney to the bladder through the ureter. The constrictions in the ureter develop the critical regions for ureter disease. ANSYS-CFX is used to analyze the flow dynamics. Multiple peristalsis waves are made to propagate over the tapered ureter model to understand the formation of bolus and reflux effect. The effect of the peristaltic sinusoidal wave propagating along the tapered circular tube results in pressure, velocity, pressure gradient, and wall shear distribution inside the ureter. The maximum pressure is created by the urine bolus of the single wave as it flows in front of the ascending urine bolus. This creates a negative pressure gradient, which can lead to a reverse flow. The high wall shear stress may affect the function of the kidney and play an important role in various kidney diseases. In triple wave due to incomplete wave propagation at the end, the minimum pressure gradient is recorded at the neck region due to contraction in the area. Also, the velocity shows a reverse flow at the outlet and this may lead to some urinary infection in the ureter.
\end{abstract}

Keywords: Variable diameter; Ureter peristalsis; Computational fluid dynamics; Velocity; Pressure; Pressure gradient; Wall shear. Received: 26 October 2021; Revised: 17 November 2021; Accepted: 18 November 2021.

Article type: Research article.

\section{Introduction}

Peristalsis is a type of fluid transport that occurs when the walls of a distensible duct are expanded or contracted. In physiology, the peristaltic mechanism involves the urine transport from the kidney to the bladder through the ureter. ${ }^{[1]}$ The contraction happens during the pacemaker in the renal pelvis and transports the urine from the kidney to the bladder. ${ }^{[2,3]}$ The normal ureter length varies from 250 to 300 $\mathrm{mm}$ in a healthy person. ${ }^{[4]}$ The bolus in the ureter formed due to contraction helps the urine motion. The urine flow rate influences the contraction rate and reduces peristaltic amplitude ${ }^{[7,8]}$ The peristaltic wave travels at a rate of 20 to 60 $\mathrm{mm} / \mathrm{sec}$ through the length of the ureter. Peristalsis occurs about 1 to 8 times each second, with an average of 3 times per

${ }^{I}$ Department of Aeronautical and Automobile Engineering, Manipal Institute of Technology, Manipal Academy of Higher Education, Manipal, Karnataka, India.

${ }^{2}$ School of Engineering and Architecture of Fribourg (HEIA-FR), Member of the university of applied science western Switzerland.

3 Department of Urology, Kasturba Medical College, Manipal Academy of Higher Education, Manipal, Karnataka, India.

4 Department of Radio Diagnosis, Kasturba Medical College,

Manipal Academy of Higher Education, Manipal, Karnataka, India. second. ${ }^{[9,10]}$ Many researchers carry out the ureterdynamics study to understand the effect of peristalsis and its biomechanical behavior during the flow in the ureter.

Most of the studies are carried out on the normal constant diameter ureter. ${ }^{[1-17]}$ Only a few numerical analysis is done on the variable diameter ureter. Srivastava et al., ${ }^{[18-20]}$ studied the effect of viscosity variation on the peristalsis in non-uniform tubes and channels. They considered the tube dimension as 0.012 and $0.018 \mathrm{~cm}$ inlet and outlet, respectively. For the analysis, the length of the ureter was assumed to be $20 \mathrm{~cm}$ with $20 \mathrm{~cm} / \mathrm{s}$ as the wave speed. They found that pressure reduces as viscosity lowers, while pressure increases as flow rate and fluid velocity decrease. Mishra et al., ${ }^{[21]}$ considered the axisymmetric circular tube with a variable cross-section for the peristalsis flow. For the analysis, they considered the tapered ureter length of $20 \mathrm{~cm}$, wave velocity of $10 \mathrm{~cm} / \mathrm{sec}$, and a radius is considered as 0.01 to $4 \mathrm{~cm}$. They concluded that, when the wave number is changed, there is no change in the Reynolds number and velocity. Eytan et al..$^{[22]}$ analyzed the two-dimensional finite non-uniform channel for the peristalsis flow as the uterus. For the tapered wall, the effect of the flow field due to phase shift and angle effect was analyzed. They found that when the contraction is out of phase, the velocity, pressure, and flow rates are reduced. 


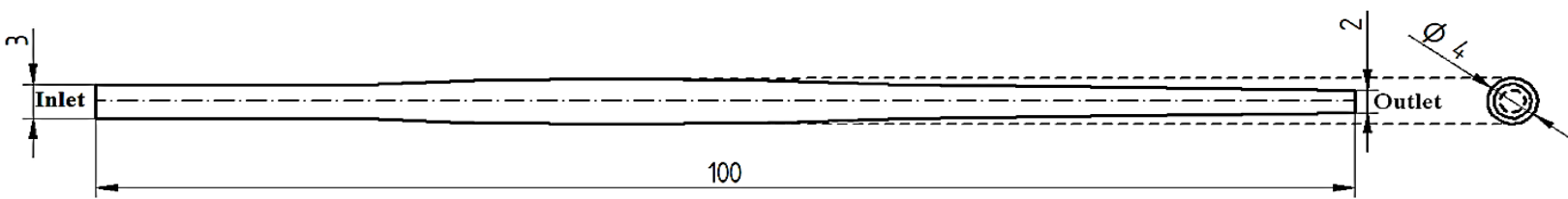

all dimesnion are in ' $\mathrm{mm}$ '

Fig. 1 Tapped ureter geometry.

They observed that the reflux phenomenon when the wall angle is more and trapping is enhanced as the wall angle is small. The majority of the studies focus on flow dynamics in the ureter using a constant diameter ureter. Najafi et al. ${ }^{[23,24]}$ used the models of 2D and 3D obstructed constant diameter ureter. They studied the backflow, tapping, and reflux phenomenon in the ureter. They concluded that as the percentage of blockage increases the pressure gradient, the wall shear stress also increases.

The mechanical properties of the ureter are one of the key factors for the fluid-structure interaction analysis. ${ }^{[24-27]}$ Takaddus et. al. ${ }^{[28,29]}$ considered the two-dimensional and three-dimensional circular tubes to study the effect of flow on the wall. The fluid's pressure gradient, shear stress, and reflux were studied using two-way fluid-structure interaction (FSI). Vahidi et al. ${ }^{[30]}$ adopted the actual ureter model to study the ureter dynamics. The two-dimensional FSI model is used for the analysis. They demonstrated that urine reflux to the kidney happens as a result of the wave start and that as the wave moves to the outlet, the reflux at UPJ (ureteropelvic junction) decreases. The researchers ${ }^{[18-22]}$ considered the peristalsis activity on the tapered organ and researchers ${ }^{[23-30]}$ adopted the constant diameter ureter to understand the ureterdynamics during peristalsis ${ }^{[31]}$ With the advancement in computational techniques, finite element analysis is used widely in medical applications. ${ }^{[32,33]}$ The functioning of human organs can be studied using the finite element method (FEM), which indeed does not require any intervention during the primary investigation. Also, FEM is widely used to evaluate the mechanical properties of medical implants. ${ }^{[34-36]}$

In this work, a three-dimensional tapered ureter is adopted to analyze the peristaltic effect during multiple wave propagation. For the urodynamics analysis, the pressure, velocity, and wall shear effect during the peristalsis wave motion is investigated.

\section{Material and methods}

\subsection{Modelling and meshing}

The narrowing of the ureter is observed at the ureteropelvic

${ }^{5}$ Department of Biological Functions and Engineering, Kyushu

Institute of Technology, Japan.

${ }^{6}$ Department of Mechanical and Manufacturing Engineering,

Manipal Institute of Technology, Manipal Academy of Higher

Education, Manipal, Karnataka, India.

\# These authors contributed to this work equally.

*Email: mohammad.zuber@manipal.edu (Mohammad Zuber) junction and ureterovesical junction (UVJ), and the iliac vascular transition. These three regions are critical regions for ureter disease. ${ }^{[37]}$ As per the urogram analysis, the anatomical dimension of the ureter diameter varies from 2 to $8 \mathrm{~mm}^{\left[{ }^{[38-40]}\right.}$ The total length of the ureter is divided into three parts, i.e., upper ureter $1 / 3$, extending from ureteropelvic junction to upper border of sacrum, middle ureter $1 / 3$, extending from upper to lower border of sacrum, and lower ureter (distal or pelvic ureter) $1 / 3$, extending from lower border of the sacrum to the bladder. ${ }^{[40]}$ The length of the ureter varies from 220 to $300 \mathrm{~mm} \cdot{ }^{[41-43]}$ The segmental anatomy length can vary from 74 to $100 \mathrm{~mm} \cdot{ }^{[40]}$ For the multiple peristalsis wave motion over the ureter, a length of $100 \mathrm{~mm}$ is considered. Fig. 1 shows the variable diameter ureter of length $100 \mathrm{~mm}$. The ureter model is modeled in ANSYS 2021-R2, with an inlet diameter of 3 $\mathrm{mm}$ and an outlet diameter of $2 \mathrm{~mm}$. The diameter of $4 \mathrm{~mm}$ is considered to mimic the actual ureter junctions. ANSYS- CFX is used to analyze the computational dynamics of the tapered ureter.

The continuity and momentum equations are used to create the pressure equation. The pressure corrects the velocity field, so satisfying the continuity condition. A second-order upwind scheme is adopted for scheming pressure and momentum. ${ }^{[30]}$ The tapered ureter model has meshed with a total number of 79091 elements and 69552 nodes using diffusion-based smoothing and mesh motion (Fig. 2). The analysis is simulated for a total wave cycle of $9 \mathrm{~s}$ at the time set of $0.05 \mathrm{~s}$.

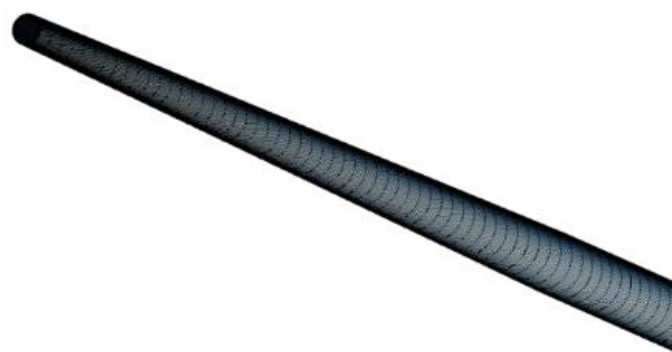

Fig. 2 Cross-section of the meshed structure of the ureter.

\subsection{Boundary condition}

For a tapering ureter model, a total pressure differential of 0.3 $\mathrm{Pa}$ is used as a boundary condition at the intake and outflow. For the ureter wall and the urine inside the ureter no slip, and no penetration is considered. ${ }^{[43-45]}$ By using Equation 3, a moving mesh method is added to the ureter wall.

\subsubsection{Governing equation}

Urine is treated as a Newtonian fluid that is a homogeneous, 

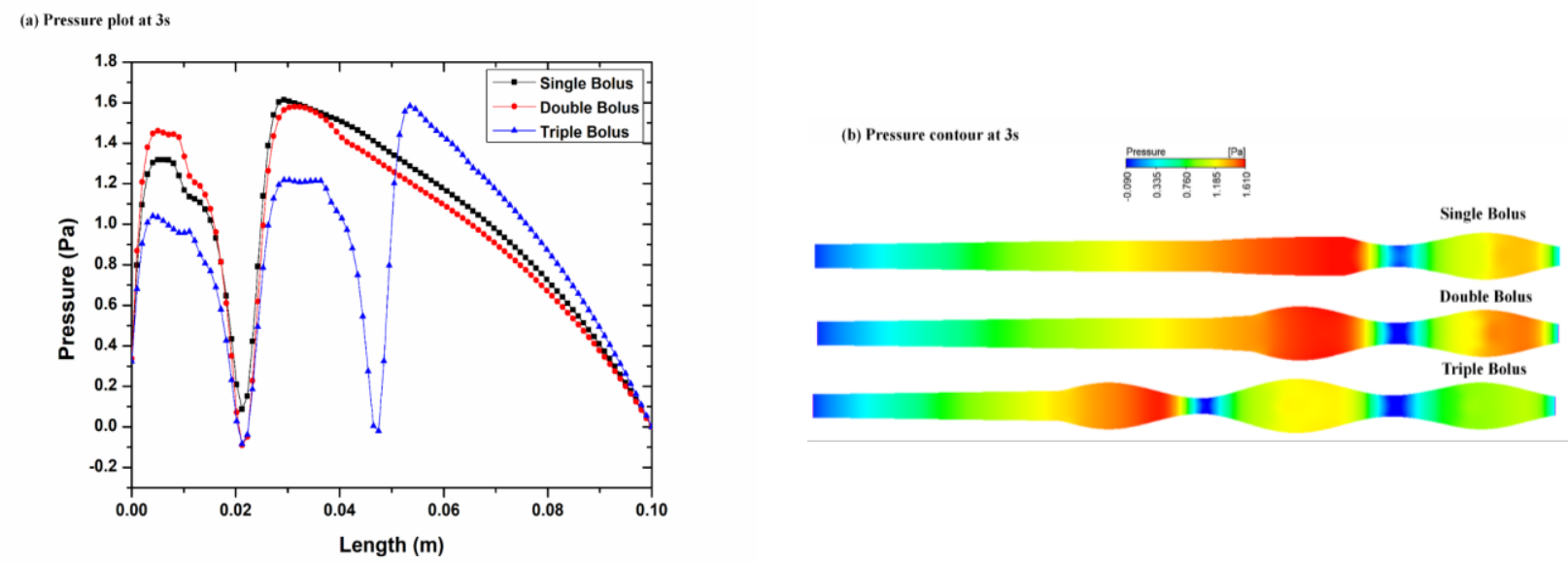

Fig. 3 Ureter Pressure for single, double, and triple wave motion for time 3s (a) pressure plot (b) pressure counter.

viscous, and incompressible fluid. The Navier-Stokes equation is used for the analysis, with density $=1050 \mathrm{~kg} / \mathrm{m}^{3}$ and viscosity $=1.3 \mathrm{cP} \cdot{ }^{[46]}$

The continuity equation is given by Equation (1):

$$
\nabla . u_{f}=0
$$

The momentum equation is given by Equation (2):

$$
\frac{\partial u_{f}}{\partial t}+\left(u_{f} \cdot \nabla\right) u_{f}=-\nabla p+\frac{\mu}{\rho}\left(\nabla^{2} u_{f}\right)
$$

where $u_{f}$ is velocity vector, $p$ is the pressure, $\rho$ is density and $\mu$ is fluid dynamic viscosity. The simple algorithm handles the pressure components in momentum equations and employs an iterative technique to acquire the solution to the discretized equations. ${ }^{[4]]}$

\subsubsection{Peristaltic motion}

During the peristalsis motion in the ureter, the velocity varies from 20 to $60 \mathrm{~mm} / \mathrm{sec}^{[48]}$ In the current work, the sinusoidal wave is accelerated at the velocity of $20 \mathrm{~mm} / \mathrm{sec}$ on the tapered ureter wall.

The tapered ureter wall displacement is considered as per Equation 3:

$$
d(z, t)= \pm a \sin (k z) \sin (\omega t)
$$

where $\mathrm{a}=1 \mathrm{~mm}$, the amplitude of displacement, $\mathrm{k}=$ wave

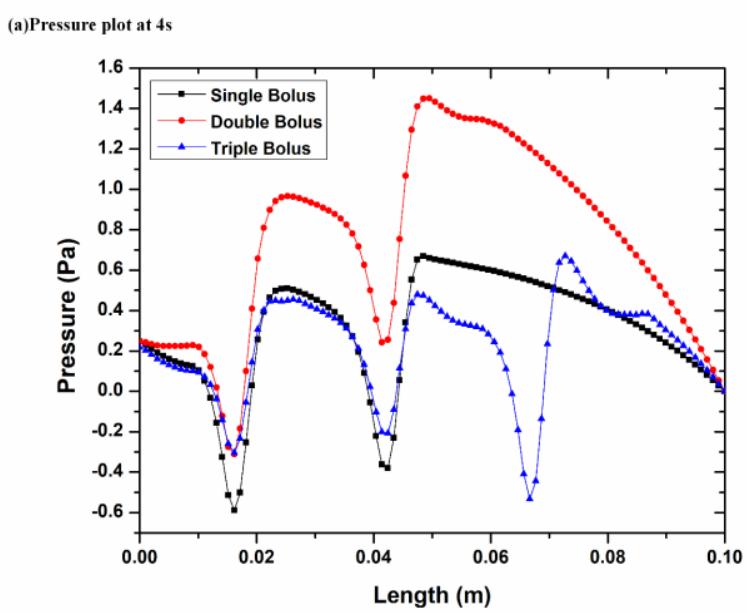

number (considered as 2 for the single wave, 4 for the double wave, and 6 for the triple wave), and $\omega=$ frequency $(1 \mathrm{~Hz})$.

\section{Result and discussion}

(1) carried out on a variable diameter ureter. The simple algorithm handles the pressure components in momentum equations and employs an iterative technique to acquire the solution to the discretized equations. For the threedimensional peristaltic flow analysis, discretized local pressure and velocity are analyzed depending on the applied boundary conditions. The results for the ureterdynamics were obtained for the total wave cycle of $9 \mathrm{sec}$ with a wave velocity of $20 \mathrm{~mm} / \mathrm{sec}$. The pressure, velocity, and wall shear are analyzed for time intervals from 3 to 6 sec.

\subsection{The pressure contour analysis}

At the time $3 \mathrm{~s}$, the bolus is formed and starts moving towards the outlet. At this time step, it was found that a maximum pressure of $1.61 \mathrm{~Pa}$ in the single bouls and a minimum pressure of $-0.09 \mathrm{~Pa}$ in the double bolus wave motion as shown in Fig. 3 (a). Maximum pressure is created in front of the propagating urine bolus during a single bolus as the wave travels to the output. The maximal pressure is recorded behind the bolus in the double and triple bolus motions.

Fig. 4 Ureter pressure for single, double, and triple wave motion for time $4 \mathrm{~s}$ (a) pressure plot and (b) pressure counter. 

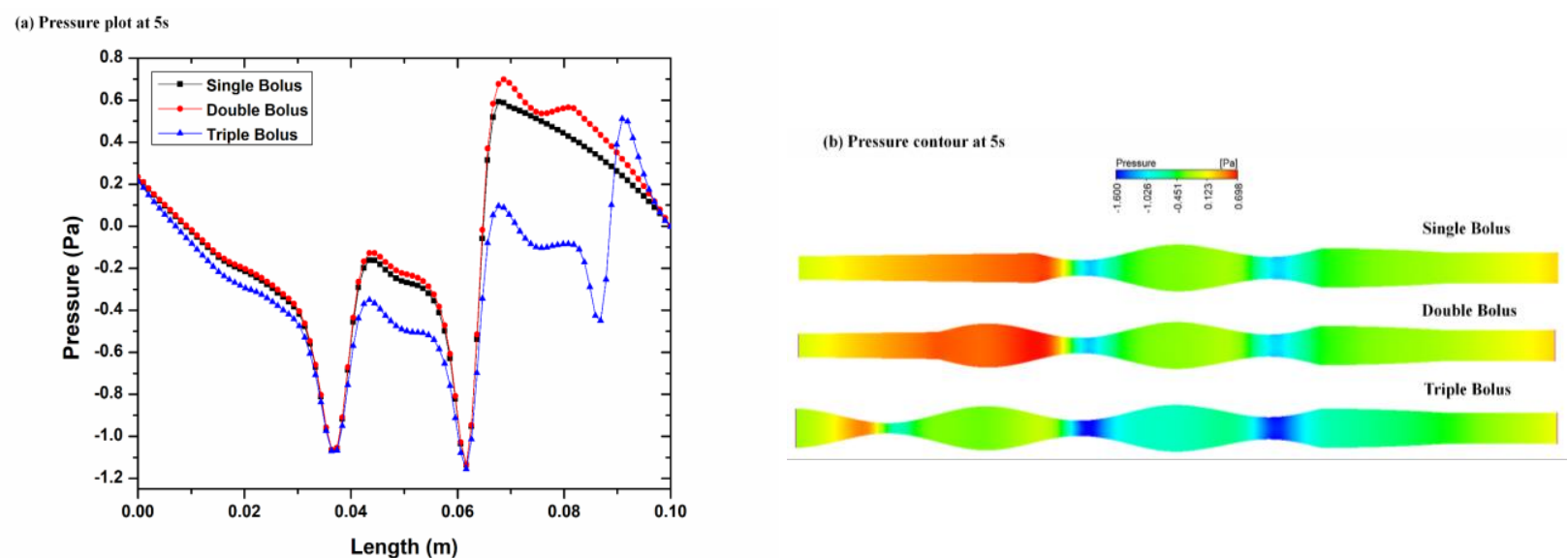

Fig. 5 Ureter pressure for single, double, and triple wave motion for time $5 \mathrm{~s}$ (a) pressure plot (b) pressure counter.

At $4 \mathrm{sec}$, it was observed that the double bolus motion will dominate the pressure magnitude as shown in Fig. 4(a), it is because of the reduction in the area towards the outlet and the distribution of the pressure due to bolus formation. The maximum pressure of $1.45 \mathrm{~Pa}$ is observed in the double bolus and the minimum pressure of $-0.59 \mathrm{~Pa}$ in the single bolus (Fig. 4(b)).

At the time $5 \mathrm{~s}$, the maximum pressure of $0.698 \mathrm{~Pa}$ was observed in the double bouls wave motion. The minimum pressure of $-1.16 \mathrm{~Pa}$ was found in the triple wave motion as shown in Fig. 5(a).

Figure 6 shows the pressure plot (Fig. 6(a)) and pressure contour (Fig. 6(b)) at the time of $6 \mathrm{sec}$. At this time, the wave travels to the diverged area. Due to this, the maximum pressure of $0.5 \mathrm{~Pa}$ was found in single bouls motion and the minimum

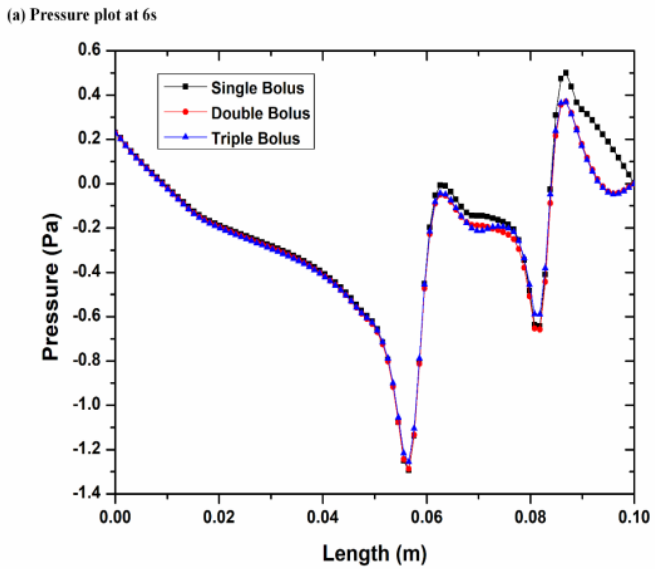

pressure of $-1.26 \mathrm{~Pa}$ was found in a triple wave.

For all the pressure plots (Fig. 3 to Fig. 6), it is clear that the maximum pressure magnitude is recorded in the bolus, and negative pressure is recorded in the neck of the bolus. The negative pressure leads to a reverse flow in the neck due to the peristaltic wave and reduction in the area of the ureter.

It is also seen that the pressure decreases as the wave travels to the outlet (Fig. 7). Weinberg et al. ${ }^{[47]}$ reported that for a single bolus of a normal diameter ureter, the greatest pressure is created behind the propagating urine bolus. In the variable diameter ureter, it is observed that for the single bolus wave motion, the pressure is generated in front of the bolus. It is also found that the maximum negative pressure is increased as the peristalsis travels to the outlet.

Fig. 6 Ureter pressure for single, double, and triple wave motion for time $6 \mathrm{~s}$ (a) pressure plot (b) pressure counter.
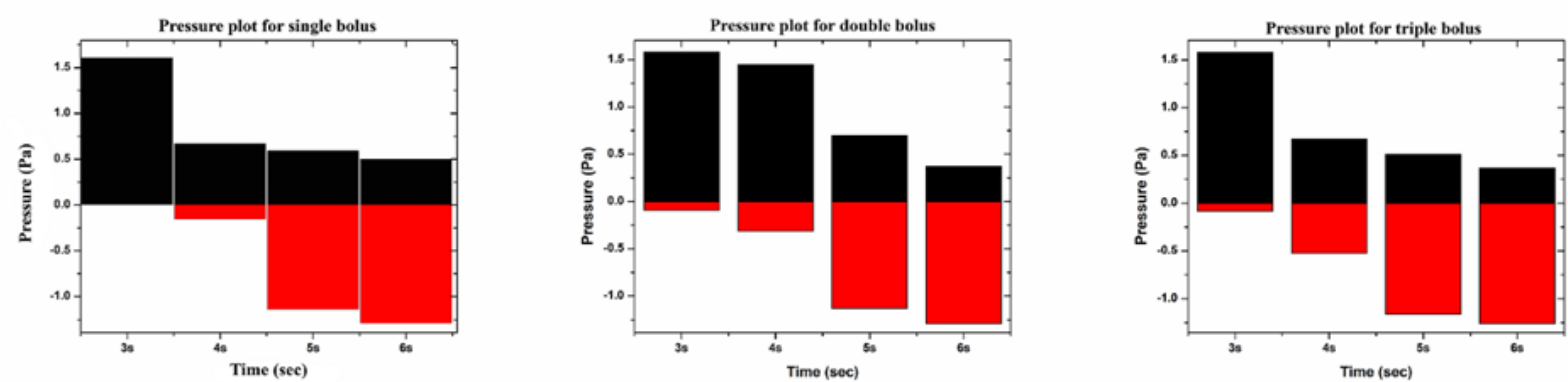

Fig. 7 Pressure plot for the single, double and triple bolus for the time 3, 4, 5, and $6 \mathrm{~s}$. 

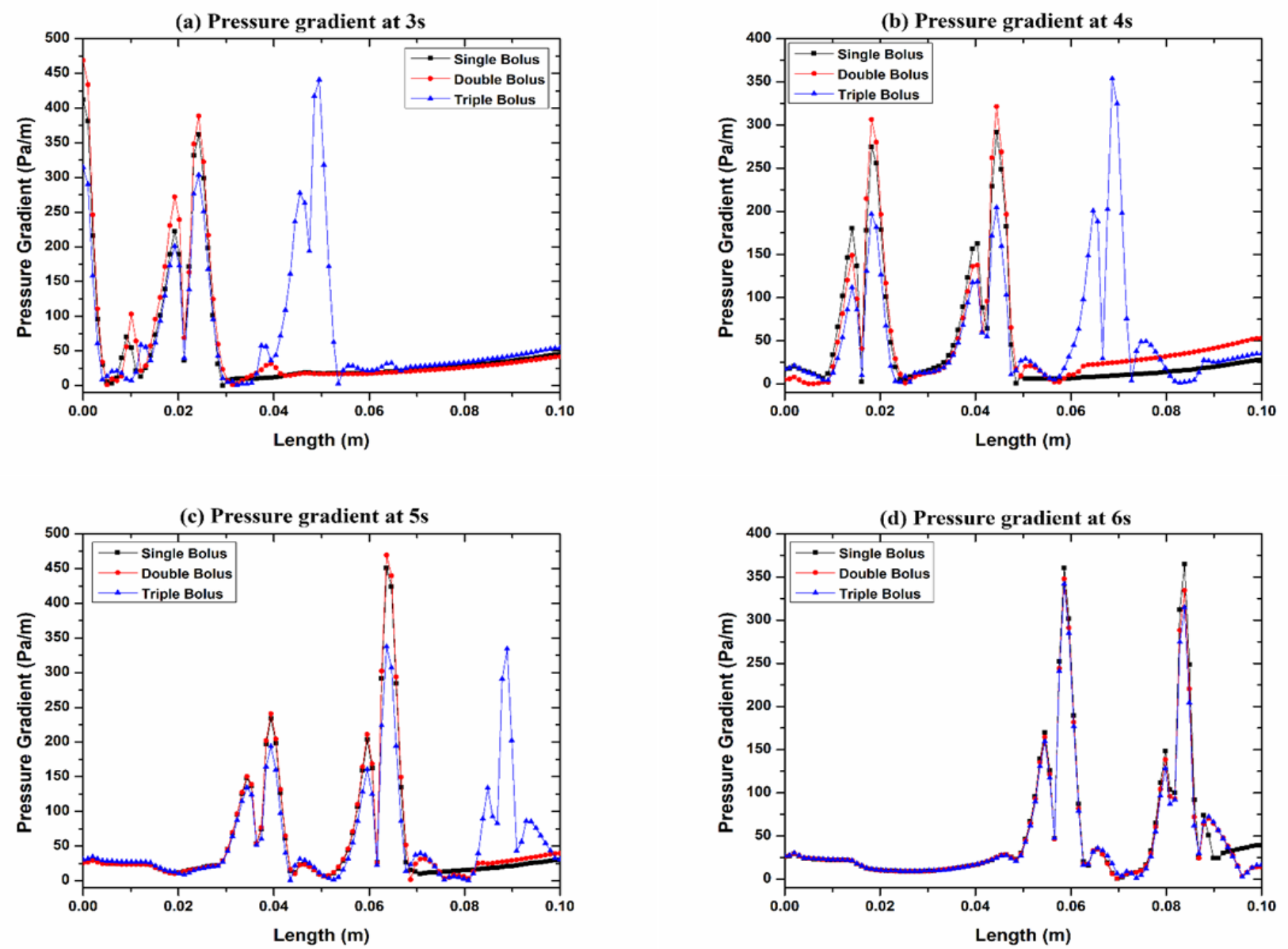

Fig. 8 Pressure gradient along the ureter axis at (a) 3, (b) 4, (c) 5, and (d) 6 sec.

\subsection{The pressure gradient analysis}

The pumping efficiency may be defined by raising pressure over a characteristic length $(\mathrm{dp} / \mathrm{dz})$ since the flow in the moving frame is constant. Fig. 8 depicts the pressure gradient along the ureter axis for four distinct time steps in a triple wave motion. Peristalsis causes the high-pressure gradient surrounding the ureter's contraction. It is found that when the wave propagates in the longitudinal direction to the bladder, the gradient peaks diminish for the normal-sized ureter. But in the variable diameter ureter, it is clear from the plot that for all the time steps, there is an increase in the pressure gradient as the wave travels to the outlet. The same observation is observed for single, double, and triple bolus motion.

The maximum pressure gradient of $450 \mathrm{~Pa} / \mathrm{m}$ is recorded for double bolus motion for the time of $3 \mathrm{sec}$. This is because of the wall contraction at the neck near the inlet as shown in Fig. 8(a). These peaks in the plots are caused by high and low pressure. In the single and double wave propagation, it is observed that flow transition causes an increase in the pressure gradient as the wave propagates to an outlet (Figs. 8(b) and $8(\mathrm{c}))$. In triple due to incomplete wave propagation at the end, the minimum pressure gradient is recorded at the neck region due to contraction in the area as shown in Fig. 8(d).

According to Vahidi et al. ${ }^{[4]}$ and Keni et al. ${ }^{[43]}$ when a peristalsis wave propagates from inlet to outlet in a normal diameter ureter, a rise in the pressure gradient value is recorded owing to ureter wall contraction. However, when the wave propagates to the exit, the pressure gradient magnitude increases in the variable diameter ureter.

\subsection{The velocity contour analysis}

Figures $9(\mathrm{a} \& \mathrm{~b})$ shows the velocity plot and velocity flow vector at the time $3 \mathrm{~s}$, respectively. It is observed that a maximum velocity magnitude of $0.0408 \mathrm{~m} / \mathrm{s}$ is found in the ureter of triple bolus motion. The other two bolus motions will not affect the flow. But the velocity of the jet is produced in the neck region of the ureter. At this region, the reverse flow is observed. As the wave propagates further, it is observed that at time $4 \mathrm{~s}$, the maximum velocity is found in the bouls of the triple wave as shown in Figs. 10(a) and 10(b). It is because of the boundary condition and the reduction in the geometrical area.

Figures 11 and 12 show a plot for 5 and 6 s. Due to incomplete wave propagation, a maximum magnitude of $0.0403 \mathrm{~m} / \mathrm{sec}$ of velocity is recorded in the triple wave at the exit of the ureter. It is clear from the velocity plot that there is a reverse flow at the neck region of the ureter. As the wave travels at the outlet, the reverse flow is observed and this may lead to some urinary infection in the ureter. Also as compared to the single and double bolus wave motion, the area of contraction is more in the triple wave motion. Because of this contraction in the area, the reverse flow occurs in the ureter. 
(a) Velocity plot at $3 \mathrm{~s}$

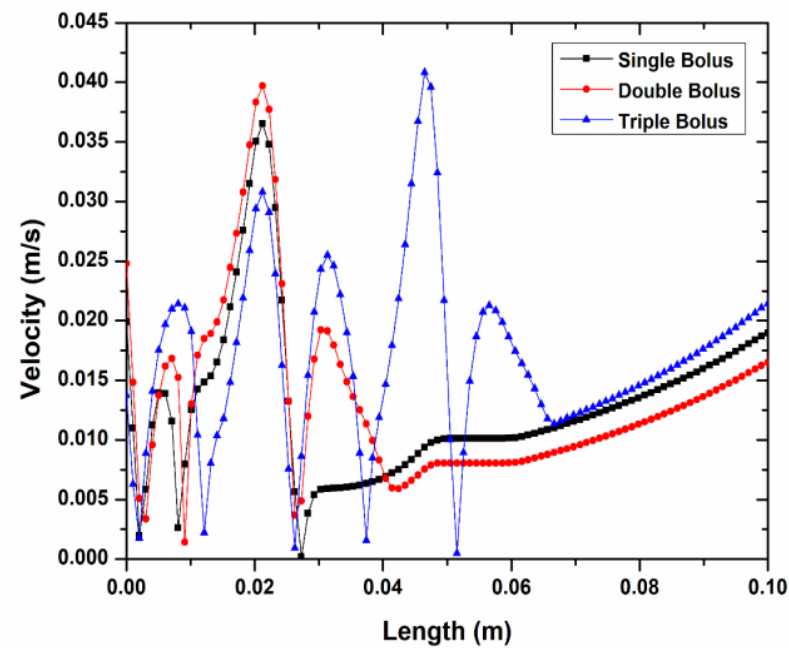

(b) Velocity flow vector at $3 \mathrm{~s}$

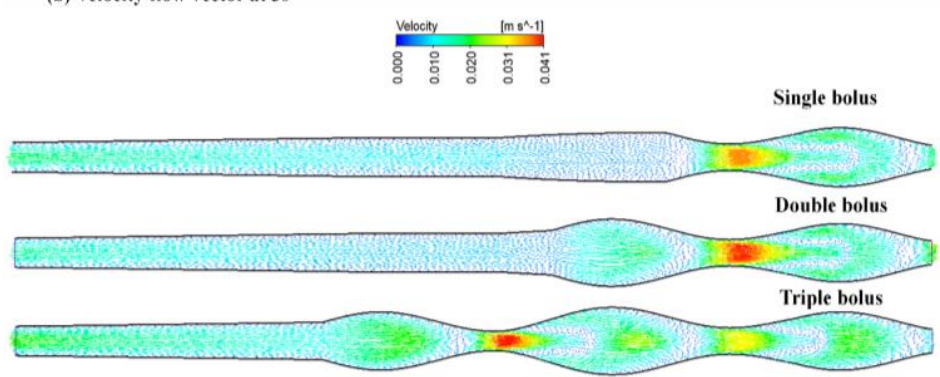

Fig. 9 Ureter velocity for single, double, and triple wave motion for time 3s (a) pressure plot (b) pressure counter.

(a) Velocity plot at $4 \mathrm{~s}$

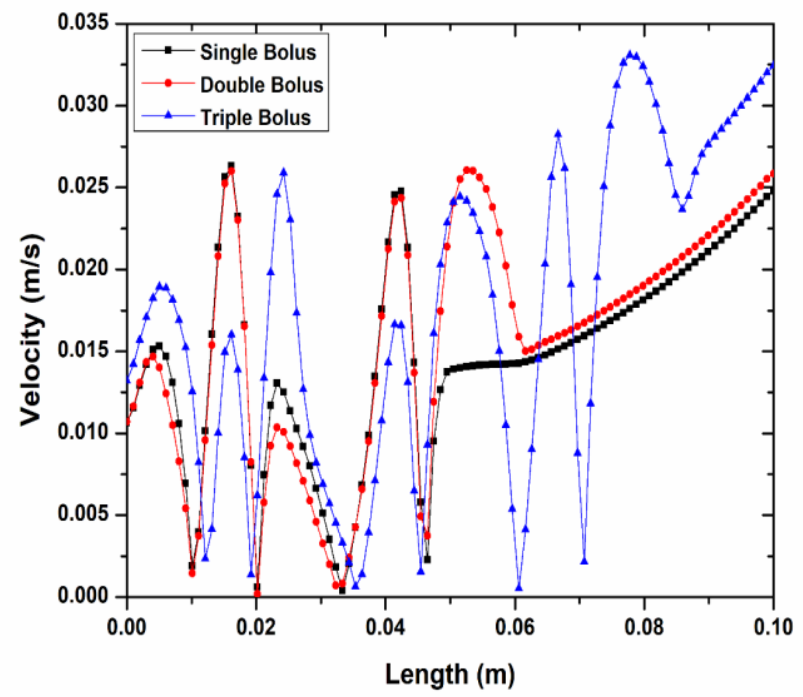

(b) Velocity flow vector at $4 \mathrm{~s}$
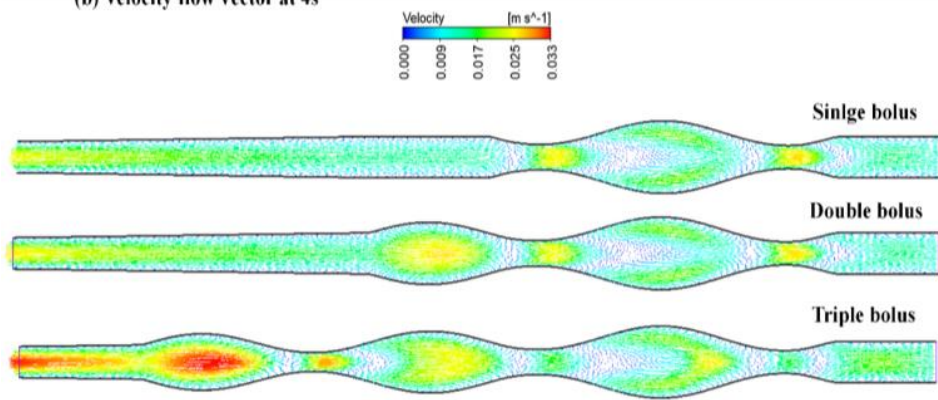

Fig. 10 Ureter velocity for single, double, and triple wave motion for time 4s (a) pressure plot (b) pressure counter.

(a) Velocity plot at $5 \mathrm{~s}$
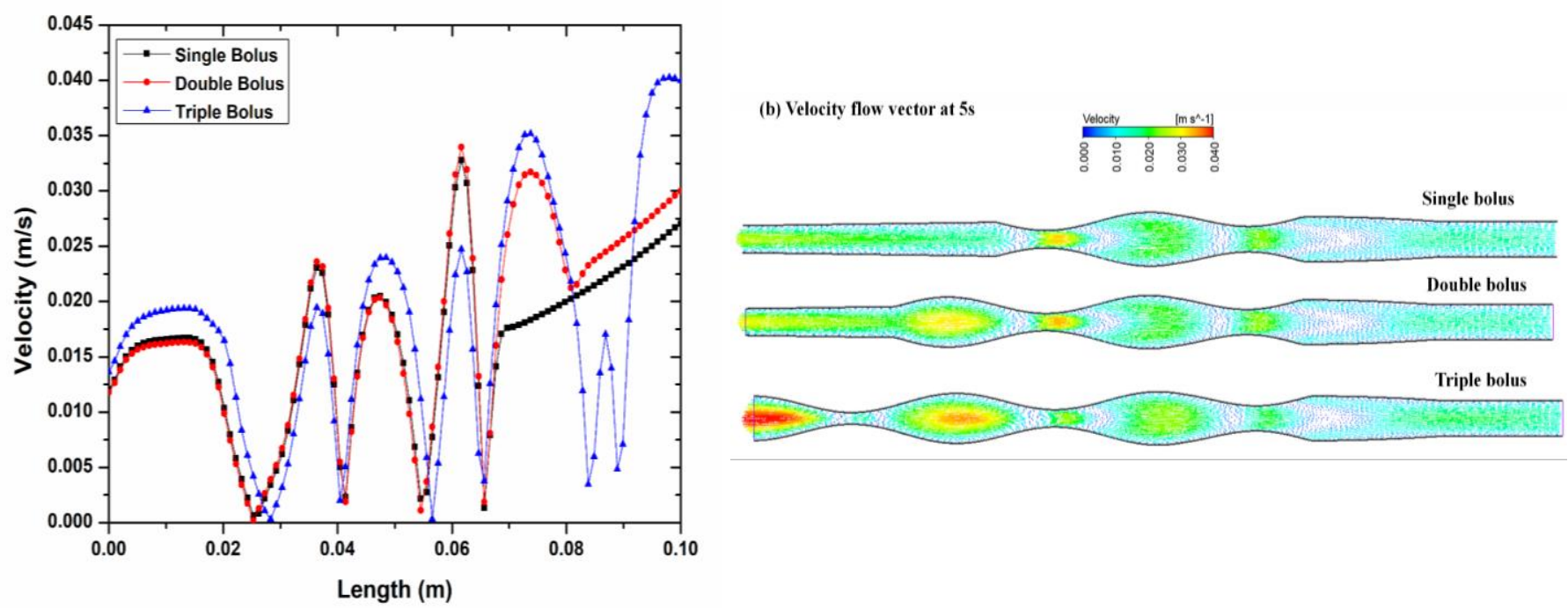

Fig. 11 Ureter velocity for single, double, and triple wave motion for time 5s (a) pressure plot (b) pressure counter. 

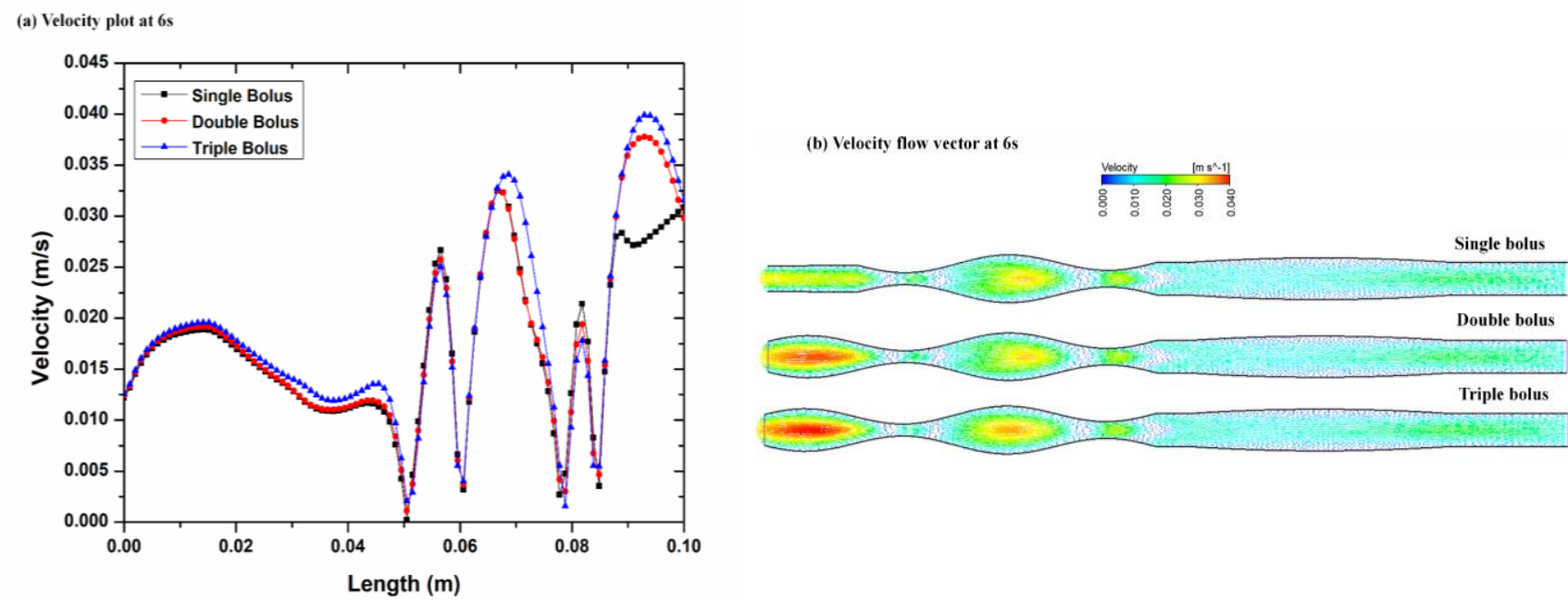

Fig. 12 Ureter velocity for single, double, and triple wave motion for time 6s (a) pressure plot (b) pressure counter.
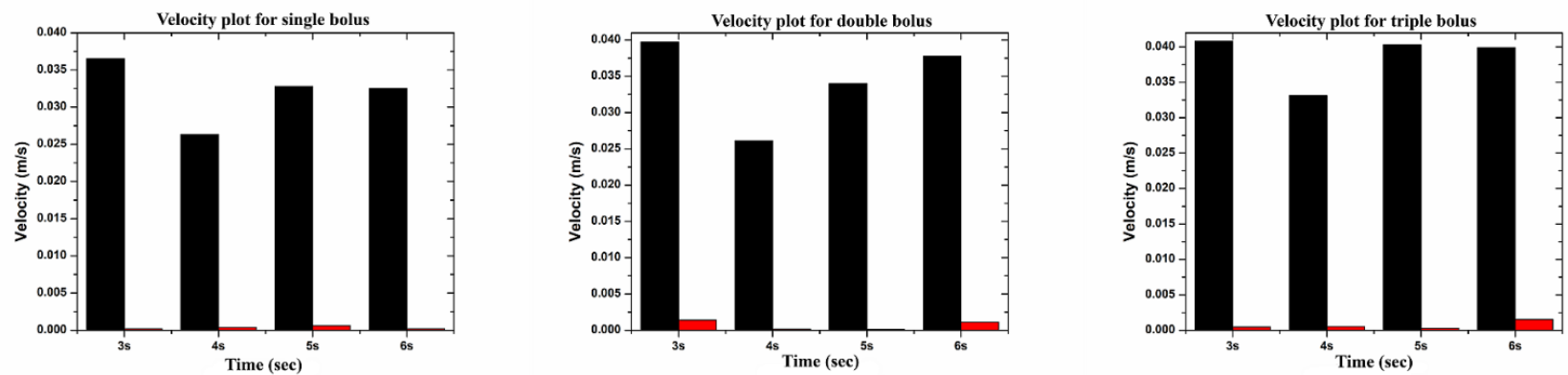

Fig. 13 Velocity plot for single bolus, double bolus, and triple bolus for the time 3, 4,5, and $6 \mathrm{~s}$.

Figure 13 shows the overall maximum and minimum velocity developed for the single, double, and triple bolus wave motion. It is clear from the graph that the high magnitude velocity is developed as the urine enters the ureter at the beginning of the flow. Further, the velocity vector plot (Fig. 9(b)) shows that at the time $3 \mathrm{~s}$ for all the bouls, the reverse flow occurs at the inlet of the ureter. Also as the wave propagates to the outlet, the reverse flow at the inlet disappears (Fig. 10(b), Fig. 11(b), and Fig. 12(b)).

\subsection{The wall shear stress}

Figure 14 shows the wall shear stress during the flow at the four-time steps. The peaks are visible in the wall shear stress plot corresponding to the time and contraction location. On further observing the behavior of wall shear stress, a comparative average value is evident at the bolus, which is then followed by abrupt jumps in wall shear stress towards both maximum and minimum direction at the contractile waves. As the wave propagates due to a high reduction in the area, a high magnitude of wall shear is observed. As the peristalsis wave starts propagating, a high stress of $0.098 \mathrm{~Pa}$ is recorded at the beginning of the triple bolus motion (Fig. 14(a)). But as the wave propagates further, a decrease in the magnitude is observed. Also, at time $5 \mathrm{~s}$ in the double bolus wave motion, a rise in the magnitude is observed of $0.089 \mathrm{~Pa}$, this is because of the reduction in the area due to the peristalsis wave (Fig. 14c).

\section{Conclusion}

The peristalsis wave effect on the tapered ureter wall is investigated at time-step intervals from 3 to $6 \mathrm{~s}$. It was observed that for the variable diameter ureter at the time $3 \mathrm{~s}$, the urine bolus enters the ureter. As the wave travels to the outlet, it is observed that maximum pressure is generated in front of the propagating urine bolus for a single bolus. In the double and triple bolus motion, the maximum pressure is observed behind the bolus. As the wave travels to the outlet, the pressure will decrease. The maximum pressure magnitude is recorded in the bolus, and negative pressure is recorded in the neck of the bolus. The negative pressure leads to a reverse flow in the neck due to the peristaltic wave and reduction in the area of the ureter. The reverse flow advances the urinary tract infection and results in the bacteria and toxins from the UPJ to the kidney. This may further lead to serious kidney problems over some time. Similarly, a high wall shear is observed in the neck region of the propagating peristalsis wave due to a high reduction in the area. The shear stress may affect the function of the kidney and play a major role in various kidney diseases. For the pressure gradient, in the single and double wave propagation, it is observed that the flow transition causes an increase in the pressure gradient as the wave propagates to an outlet. In triple wave due to incomplete wave propagation at the end, the minimum pressure gradient is recorded at the neck region due to contraction in the area. Also, it is clear from the velocity plot that there is a reverse 
(a) Wall shear at $3 \mathrm{~s}$

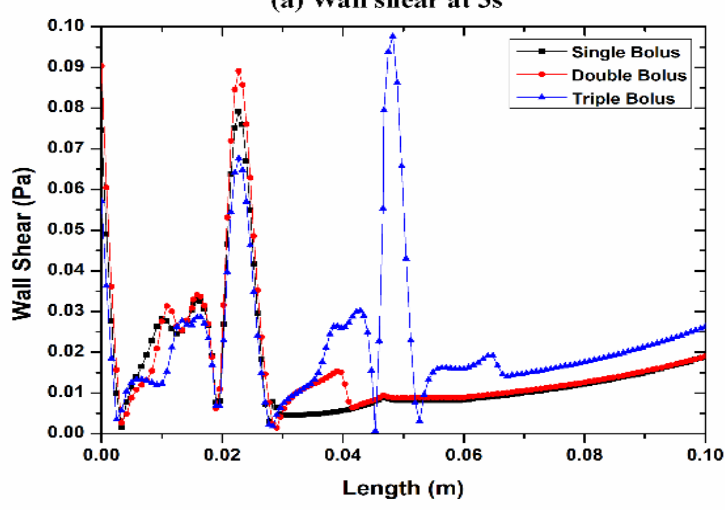

(c) Wall shear at $5 \mathrm{~s}$

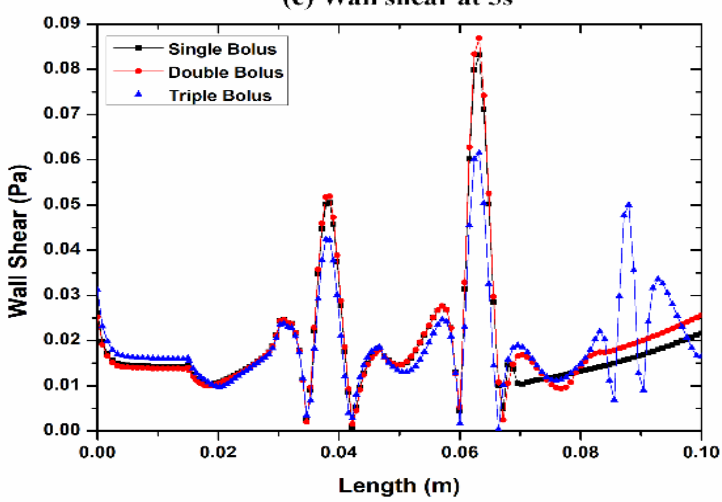

(b) Wall shear at $4 \mathrm{~s}$

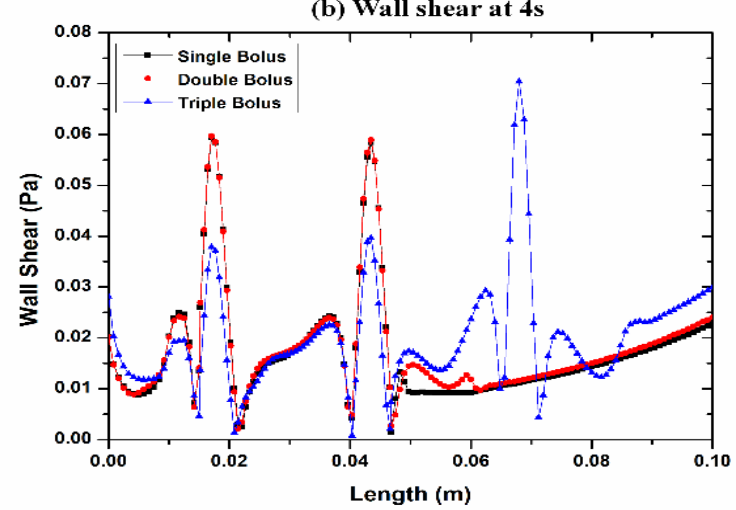

(d) Wall shear at $6 \mathrm{~s}$

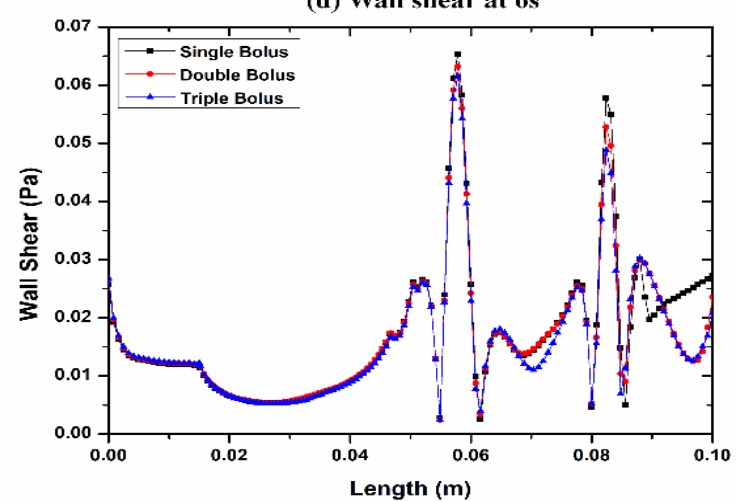

Fig. 14 wall shear stress along the ureter axis. (a) at $3 \mathrm{sec}(\mathrm{b})$ at $4 \mathrm{sec}(\mathrm{c})$ at $5 \mathrm{sec}$ (d) at $6 \mathrm{sec}$.

flow observed outlet and this may lead to some urinary infection in the ureter. Also, when compared to the single and double bolus wave motion, the area of contraction is more in the triple wave motion. Because of this contraction in the area, the reverse flow occurs in the ureter. Further experimental work can be carried out by manufacturing ureter tubes using suitable rapid prototyping techniques, which helps to understand the effect of shear stresses on constrictions of the ureter.

\section{Acknowledgments}

The authors thank the Department of Aeronautical and Automobile Engineering, Manipal Institute of Technology, Manipal Academy, Manipal for providing the high computational facility to carry out this research.

\section{Conflict of interest}

There are no conflicts to declare.

\section{Supporting information}

Not applicable.

\section{References}

[1] L. M. Srivastava, V. P. Srivastava, S. N. Sinha, Biorheology, 1983, 20, 179-185, doi: 10.3233/bir-1983-20207.

[2] M. M. Feeney, N. D. Rosenblum, Pediatric Nephrology, 2014, 29, 629-635, doi: 10.1007/s00467-013-2631-4.

[3] F. T. Hammad, Acta Physiologica, 2015, 213, 371-383, doi: 10.1111/apha.12392.

[4] D. Venkatesh, H. H. Sudhakar, Indian journal of physiology and pharmacology, 2001, 45, 227-232.

[5] J. E. Hall, T. R. Simon, J. A. Mercy, R. Loeber, D. P. Farrington, R. D. Lee, American journal of preventive medicine, 2012, 43, S1-S7, doi: 10.1016/j.amepre.2012.04.026.

[6] V. Mahadevan, Surgery (Oxford), 2016, 34, 318-325, doi: 10.1016/j.mpsur.2016.04.001

[7] A. Kondo, Nagoya journal of medical science, 1970, 32, 387394, doi: 10.18999/nagjms.32.3-4.387.

[8] R. V. Krstić, Human microscopic anatomy: an atlas for students of medicine and biology, 1991.

[9] S. L. Weinberg, M. Y. Jaffrin, A. H. Shapiro, Amsterdam: Elsevier, 1971, 217-231, doi: 10.1016/b978-0-12-1212506.50024-1.

[10] S. R. Weinberg, JAMA, 1961, 175, 15, doi: 10.1001/jama.1961.03040010017005.

[11] J. C. Gómez-Blanco, F. J. Martínez-Reina, D. Cruz, J. B. Pagador, F. M. Sánchez-Margallo, F. Soria, Computational and Mathematical Methods in Medicine, 2016, 2016, 1-7, doi: 10.1155/2016/5710798.

[12] S. Zheng, D. Carugo, A. Mosayyebi, B. Turney, F. Burkhard, D. Lange, D. Obrist, S. Waters, F. Clavica, WIREs Mechanisms of Disease, 2021, 13, e1523, doi: 10.1002/wsbm.1523.

[13] Z. Najafi, B. F. Schwartz, A. J. Chandy, A. M. Mahajan, Computer Methods in Biomechanics and Biomedical Engineering, 2018, 21, 22-32, doi: $10.1080 / 10255842.2017 .1415333$. 
[14] A. T. Takaddus, A. J. Chandy, Computer Methods in Biomechanics and Biomedical Engineering, 2018, 21, 750-759, doi: 10.1080/10255842.2018.1516764.

[15] R. J. Lang, M. A. Tonta, B. Z. Zoltkowski, W. F. Meeker, I. Wendt, H. C. Parkington, The Journal of Physiology, 2006, 576, 695-705, doi: 10.1113/jphysiol.2006.116855.

[16] D. J. Griffiths, Journal of Biomechanical Engineering, 1989, 111, 206-211, doi: 10.1115/1.3168367.

[17] A. C. Kinn, Urological Research, 1996, 24, 1-7, doi: 10.1007/BF00296725.

[18] L. M. Srivastava, V. P. Srivastava, S. N. Sinha, Biorheology, 1983, 20, 153-166, doi: 10.3233/bir-1983-20205.

[19] L. M. Srivastava, V. P. Srivastava, Journal of Biomechanics, 1984, 17, 821-829, doi: 10.1016/0021-9290(84)90140-4.

[20] L. M. Srivastava, V. P. Srivastava, S. N. Sinha, Biorheology, 1983, 20, 179-185, doi: 10.3233/bir-1983-20207.

[21] J. C. Misra, S. K. Pandey, Mathematical and computer modelling, 1995, 22, 137-151, doi: 10.1016/08957177(95)00162-U.

[22] O. Eytan, A. J. Jaffa, D. Elad, Medical engineering \& physics, 2001, 23, 475-484, doi: 10.1016/S1350-4533(01)00078-9.

[23] Z. Najafi, B. F. Schwartz, A. J. Chandy, A. M. Mahajan, Computer Methods in Biomechanics and Biomedical Engineering, 2018, 21, 22-32, doi: 10.1080/10255842.2017.1415333.

[24] Z. Najafi, P. Gautam, B. F. Schwartz, A. J. Chandy, A. M. Mahajan, Journal of Biomechanical Engineering, 2016, 138, 101002, doi: 10.1115/1.4034307.

[25] L. Knudsen, H. Gregersen, B. Eika, J. Frøkiær, Neurourology and Urodynamics, 1994, 13, 597-606, doi: 10.1002/nau.1930130515.

[26] D. P. Sokolis, Computer Methods in Biomechanics and Biomedical Engineering, 2012, 15, 1145-1156, doi: 10.1080/10255842.2011.581237.

[27] G. Hosseini, J. J. R. Williams, E. J. Avital, A. Munjiza, X. Dong, J. S. A. Green, Critical Reviews in Biomedical Engineering, 2013, 41, 259-268, doi: 10.1615/critrevbiomedeng.2013009704.

[28] A. T. Takaddus, P. Gautam, A. J. Chandy, Proceedings of ASME 2016 International Mechanical Engineering Congress and Exposition, Phoenix, Arizona, USA, 2016, doi: 10.1115/IMECE2016-65999.

[29] A. T. Takaddus, P. Gautam, A. J. Chandy, International Journal for Numerical Methods in Biomedical Engineering, 2018, 34, e3104, doi: 10.1002/cnm.3104.

[30] B. Vahidi, N. Fatouraee, Journal of Theoretical Biology, 2012, 298, 42-50, doi: 10.1016/j.jtbi.2011.12.019.

[31] O Eytan, Elad, D, Bulletin of Mathematical Biology, 1999, 61, 221-238, doi: 10.1006/bulm.1998.0069.

[32] K. N. Chethan, Z. Mohammad, S. Bhat, B. Satish Shenoy, Cogent Engineering, 2020, 7, 1-14 doi: 10.1080/23311916.2020.1719575.

[33] K. N. Chethan, M. Zuber, S. Bhat N, S. Shenoy B, C. R. Kini, Heliyon, 2019, 5, e01767, doi: 10.1016/j.heliyon.2019.e01767.

[34] A. Eram, M. Zuber, L. G. Keni, S. Kalburgi, R. Naik, S. Bhandary, S. Amin, I. A. Badruddin, Computer Methods and
Programs in Biomedicine, 2020, 190, 105356, doi: 10.1016/j.cmpb.2020.105356.

[35] C. K N, G. Ogulcan, S. Bhat N, M. Zuber, S. Shenoy B, Computer Methods and Programs in Biomedicine, 2020, 196, 105597, doi: 10.1016/j.cmpb.2020.105597.

[36] B. S. Acar, S. Mihcin, International Journal of Human Factors Modelling and Simulation, 2010, 1, 380-389, doi: 10.1504/IJHFMS.2010.040272.

[37] R. B. Dyer, M. Y. M. Chen, R. J. Zagoria, RadioGraphics, 2001, 21, 799-824, doi: 10.1148/radiographics.21.4.g01j126799.

[38] S. L. Wong, H. Abdul Hamid, The Malaysian journal of medical sciences, 2010, 17, 4-9.

[39] Bradley, Desai, Mamtora, British journal of urology, 1998, 81, 682-685, doi: 10.1046/j.1464-410x.1998.00641.x.

[40] U. D. Itanyi, J. O. Aiyekomogbon, F. U. Uduma, M. A. Evinemi, African Journal of Urology, 2020, 26, 4-9, doi: 10.1186/s12301-020-00021-0.

[41] D. R. Hickling, T. T. Sun, X. R. Wu, Microbiology Spectrum, 2015, 3, 1-17, doi: 10.1128/microbiolspec.UTI-0016-2012.

[42] T. S. Kohler, M. Yadven, A. Manvar, N. Liu, M. Monga, International Brazilian Journal of Urology, 2008, 34, 451-456, doi: 10.1590/s1677-55382008000400007.

[43] L. G. Keni, M. J. Hayoz, S. M. A. Khader, P. Hegde, K. Prakashini, M. Tamagawa, B. Satish Shenoy, B. M. Z. Hameed, M. Zuber, Computer Methods and Programs in Biomedicine, 2021, 210, 106378, doi: 10.1016/j.cmpb.2021.106378.

[44] B. Vahidi, N. Fatouraee, A. Imanparast, A. N. Moghadam, Journal of Biomechanical Engineering, 2011, 133, 1, doi: 10.1115/1.4003316.

[45] N. P. Khabazi, K. Sadeghy, Journal of Non-Newtonian Fluid Mechanics, 2016, 236, 1-17, doi: 10.1016/j.jnnfm.2016.08.001.

[46] A. A. Bykova, S. A. Regirer, Fluid Dynamics, 2005, 40, 119, doi: 10.1007/s10697-005-0039-y.

[47] S. V. Patankar, CRC Press, 2018.

[48] J. N. Jimenez Lozano, PhD. Thesis Mech. Eng. Notre Dame University, Indiana, USA, 2009, 195.

\section{Author Information}

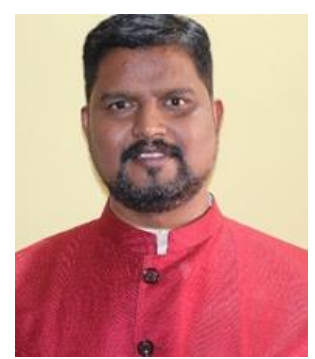

Mr. Laxmikant $\boldsymbol{G}$ Keni received Mechanical Engineering from Visweswariah Technological University, Karnataka. He completed his Masters's Degree in Computer-Aided Mechanical Design and Analysis from Manipal Institute of Technology Manipal. Pursuing his Ph.D. on ureter flow dynamics from Manipal Academy of Higher Education. His areas of interest are FluidStructure Interaction, Computational Bio-fluid Mechanics, Computational fluid dynamics, Structural Analysis, and Machine Design. Currently, he is working as Assistant Professor-Senior Grade at the Department of Aeronautical and Automobile Engineering. 


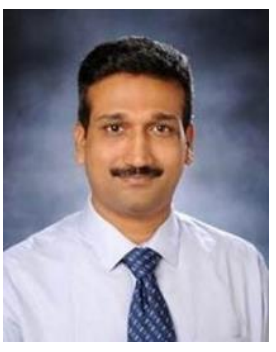

Dr. Satish Shenoy B working as a Professor in the Department of Aeronautical and Automobile Engineering, Manipal Institute of Technology, Manipal Academy of Higher Education, Manipal, Karnataka, INDIA. He holds B. E. (Mechanical Engineering), M.Tech (Manufacturing Engineering \& Technology), and Ph.D. (Tribology) degrees. He has more than Twenty of teaching and research experience. His area of interest includes Biomechanics of the hip joint, Finite element analysis of biomedical implants, Composite materials, Manufacturing of medical implants, Computational fluid dynamics.

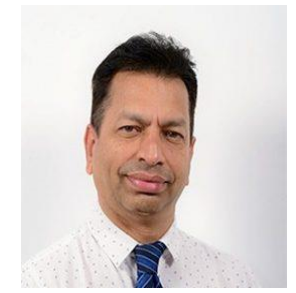

Dr. Padmaraj Hegde is one of the popular doctors in the Department of Urology at Kasturba Hospital, Manipal. He has completed his M.B.B.S, M.S.(Gen Surgery), and MCh (Urology) from the prestigious Kasturba Medical College, Manipal under Manipal Academy of Higher Education. He obtained the Fellow of the Royal College of Surgeons, Glasgow University, and Fellow of the International Medical Sciences Academy. Dr. Hegde is associated with the Department of Urology, KMC Manipal for the last 21 years and has vast experience in treating patients with urological conditions. He has a keen interest in Andrology, Stone disease, Endourology, and Male Infertility. Presently he is the Professor of Urology and Heading Unit at Kasturba medical college Hospital, Manipal.

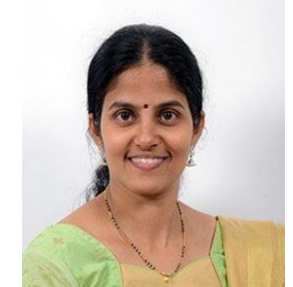

Dr. Prakashini K graduated in Medicine from Manipal Academy of Higher Education, Manipal. She completed her M.D in Radiodiagnosis from the same institute. Dr. Prakashini is presently working as Professor and Head in the Department of Radio-Diagnosis and Imaging, Kasturba Hospital, Manipal University. Her core expertise is in the domain of Advanced Ultrasound Imaging, Cardiovascular Imagining. She has several publications in the area of Cardiovascular and Abdominal Imaging.

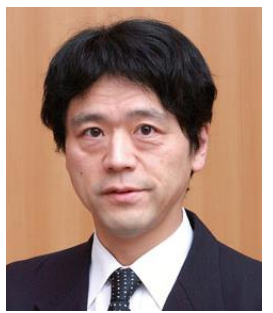

Dr. Massaki Tamagawa obtained a Bachelor of Engineering in Mechanical Engineering from the Faculty of Engineering, Kyoto University, Japan. He completed his Masters's Degree in Mechanical Engineering from the Faculty of Engineering, The University of Tokyo (Institute of Industrial Science), Japan. Earned his Ph.D. degree from the Department of Mechanical Engineering, Faculty of Engineering, Kyoto University, Japan. His areas of interest are Computational Bio-fluid Mechanics and Biomimetics. Currently, he is a professor at the Faculty of Engineering, Kyoto University, Japan.

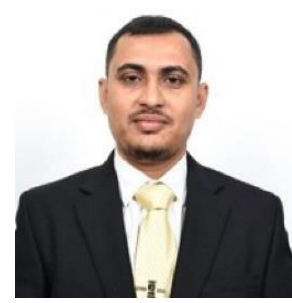

Dr. Shah Mohammad Abdul Khader obtained Mechanical Engineering from Visweswariah Technological University, Karnataka. He completed his Masters's Degree in Computer-Aided Mechanical Design and Analysis from Manipal Institute of Technology Manipal. Earned his Ph.D. degree in biofluid dynamics from Manipal University. His areas of interest are Fluid-Structure Interaction, Computational Biofluid Mechanics, CFD, Structural Analysis, and Machine Design. Currently, he is working as Associate Professor Department of Mechanical and Manufacturing Engineering.

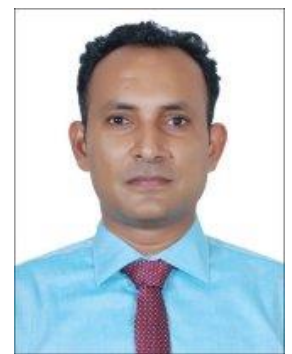

Dr. Mohammad Zuber graduated in Mechanical Engineering from Visweswariah Technological University, Karnataka. He completed his Masters's Degree in Thermal Engineering system Technology. Completed his Ph.D. on biofluid dynamics from Universiti Sains Malaysia. His areas of interest are Fluid-Structure Interaction Computational Bio-fluid Mechanics, CFD, Aerodynamics, and Biomimetics. He has worked as Post Doc Fellow at Universiti Sains Malaysia, Malaysia. He has also worked as Senior Lecturer at Dept. of Aerospace Engineering, Universiti Putra Malaysia, from 2014 to 2017. Currently, he is the Assistant Director for Innovation \& Incubation at Manipal Institute of Technology, Manipal.

Publisher's Note: Engineered Science Publisher remains neutral with regard to jurisdictional claims in published maps and institutional affiliations. 